\title{
A new multimodal membrane adsorber for monoclonal antibody purifications
}

Juan Wang ${ }^{\mathrm{a}}$, Eleanor W. Jenkins ${ }^{\mathrm{b}}$, Julie R. Robinson ${ }^{\mathrm{a}}$, Anastasia Wilson ${ }^{\mathrm{b}}$, Scott M. Husson ${ }^{\mathrm{a} *}$

${ }^{\mathrm{a}}$ Department of Chemical and Biomolecular Engineering, Clemson University, Clemson, SC, 29634, USA

${ }^{\mathrm{b}}$ Department of Mathematical Sciences, Clemson University, Clemson, SC, 29634, USA

*Correspondence: shusson@clemson.edu; Tel.: +1 (864) 656-4502; Fax: +1 (864) 656-0784

Abstract: This contribution describes research on the use of a newly developed multimodal membrane (MMM) adsorber that can be used as a chromatographic stationary phase in bioseparation processes. Compared with commercial cationic multimodal adsorbers, this MMM has superior static binding capacity $(\mathrm{SBC}=180 \mathrm{mg} \mathrm{IgG/ml})$, dynamic binding capacity ( $\mathrm{DBC}_{10 \%}$ $=60 \mathrm{mg} \mathrm{IgG/ml}$, and load productivity (>10 mg/ml/min). Furthermore, the incorporation of functional groups that provide orthogonal modes of interactions increases the range of ionic strength for operation of the MMM relative to conventional ion-exchange and hydrophobic interaction chromatography media. The effects of different salt types (kosmotropic, neutral, chaotropic salts) and ionic strength on IgG binding were investigated. To further understand the protein adsorption on the MMM, a thermodynamic model was employed to describe IgG adsorption isotherms on the MMM by providing a unique set of physically meaningful parameters for each salt type. The model was also a precise predictor of the adsorption isotherms under non-test conditions. A breakthrough analysis was used to determine dynamic binding capacities. The MMM maintained $70 \% \mathrm{DBC}$ as ionic strength increased from 0 to $300 \mathrm{mM}$ 
$\mathrm{NaCl}$. Finally, a range of flow rates was used to study the effect of volumetric throughput on DBC. Because DBC was insensitive to flow rate, process productivity increased with flow rate nearly linearly up to high linear velocity $(535 \mathrm{~cm} / \mathrm{h})$. A kinetic study indicated that the rate limiting step of IgG binding on the MMM was the adsorption rate, not the convective mass transport of protein molecules to binding sites.

Keywords: biologic, hydrophobic interaction chromatography, ion exchange, mixed-mode, protein capture

\section{Introduction}

Excellent separation resolution and mild operating conditions make chromatographic processes particularly useful in downstream protein purification operations. However, substantial improvements in downstream manufacturing processes are necessary to increase production capacities and meet the large, rapidly increasing demand for protein therapeutics. While the conventional chromatographic operations are designed to purify protein based on a single interaction mode such as affinity interaction, Coulombic interaction, hydrophobic interaction and size exclusion [1,2], multimodal chromatographic operations are used to purify protein through two or more orthogonal modes of interaction. Multimodal adsorbents have been shown to improve product quality by removal of high molecular weight aggregates and can improve process efficiency in industrial-scale $\mathrm{mAb}$ drug manufacturing [3-5]. Specifically, the advantage of multimodal operations is that they may decrease the number of purification steps, thereby shortening purification times and increasing the overall protein yields. These factors are paramount in controlling overall manufacturing capacity and protein product quality. 
Most commercial multimodal chromatographic media comprise resin beads functionalized with ligands that exhibit both hydrophobic and Coulombic properties. Exceptions are the commercial membranes from EMD-Millipore (Chromasorb) and Sartorius (Sartobind STIC ${ }^{\circledR}$ PA Nano); however, these are limited to anionic MMMs. The use of resin beads as packing media results in low productivity[6-8]. Consequently, the use of membranes has become a viable option for membrane chromatography, particularly now that strategies have been developed by our group and others to increase the binding capacities of membrane adsorbers to values that meet or exceed the corresponding resins [9-11]. Just recently, we described the use of surface-initiated atom transfer polymerization to prepare the first cationic multimodal membrane [10].

Given the promising application of multimodal membrane adsorbers for protein bind-and-elute purifications, detailed theoretical simulations of protein binding on multimodal membrane adsorbents are needed to reduce the time and cost spent on process development. While the wellknown Langmuir isotherm model used to describe convex isotherms does provide the apparent maximum binding capacity and association coefficient, it does not provide mechanistic insights on the influence of different interaction types and the mobile phase conditions on protein binding, and its constants must be adjusted for each new set of operating conditions. In attempts to overcome such limitations, Brooks and Cramer [12] developed the Steric Mass Action (SMA) formalism model, which entails the use of three parameters for determining the non-linear adsorption in an ion-exchange system. This SMA model considers the steric hindrance of salt counterions, but not the protein-protein interactions. Mollerup et al. [13] extended SMA to develop a thermodynamic model that includes interaction-type parameters, and applies to both 
hydrophobic interaction chromatography and ion exchange. Using the generalized framework developed by Mollerup et al., Ottens and coworkers [14] developed a model for protein adsorption on multimodal adsorbents functionalized with ligands carrying both hydrophobic and groups. This model has not yet been applied to membrane adsorbers.

The objectives of this study were to apply the thermodynamic model described by Ottens and coworkers [11] to analyze immunoglobulin $\mathrm{G}(\operatorname{IgG})$ adsorption on our newly developed multimodal membrane adsorbers and to evaluate membrane performance under static and dynamic protein binding conditions. Fitted model parameters were used to elucidate the protein adsorption mechanism(s) under different salt conditions (type and ionic strength). IgG dynamic binding capacities and load productivities were measured for comparison with commercial products. Using column studies, we determined the effects of flow rate and ionic strength on the dynamic binding capacities, identified the rate limiting factors for protein binding on the new MMM, and developed an effective elution strategy.

\section{Theory}

Ottens and coworkers [14] developed a thermodynamic model for protein adsorption on multimodal adsorbents and an approach for estimating the unknown model parameters. The stoichiometric exchange of protein and hydrophobic ligands with salt counterions is represented by the following reaction:

$P+v S L+n L \Leftrightarrow P L_{n}+v S$

where a protein molecule $\mathrm{P}$ is adsorbed to a stationary phase with $\mathrm{n}$ hydrophobic ligands and simultaneously exchanges with $v$ salt counter-ions to form the protein-ligand complex $P L_{n} . v$ is 
defined as the ratio of the binding charge of the protein $z_{p}$ to the charge of the salt counterion $z_{s}$ : $v=z_{p} / z_{s}$

In multimodal exchange chromatography, the general form of the single component isotherm is given by Equation 1 [14]:

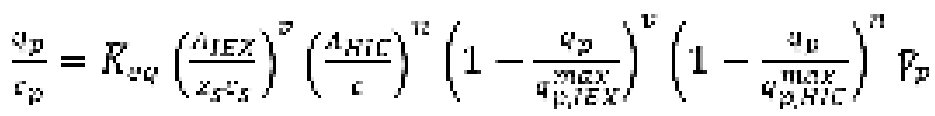

where $q_{p}$ and $c_{p}$ are the protein concentrations in the adsorbed phase and liquid phase; $q_{x . i s x}^{\text {max }}$ and $q_{x . i n c}^{\text {mux }}$ are the maximum binding capacities achieved through Coulombic interaction and hydrophobic interaction; $K_{t_{j} j}$ is the thermodynamic equilibrium constant; $c_{s}$ is the salt concentration in the liquid phase; $\mathrm{c}$ is the molarity of the solution in the pore volume; $\gamma_{\mathrm{x}}$ is the normalized activity coefficient; $A_{i \leq x}$ is the ionic-exchange ligand density; and $A_{i i y: \text { : }}$ is the hydrophobic ligand density.

Ottens and coworkers [14] point out for the case of multimodal adsorbents bearing the same number of Coulombic interaction groups and hydrophobic interaction groups that $A_{i \leq X}=A_{y i c:}=A$, and the adsorption isotherm simplifies to Equation 2:

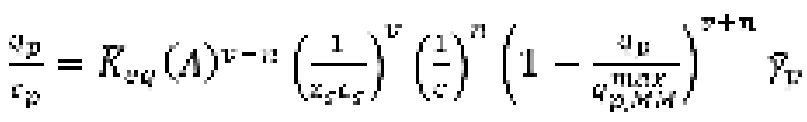

The asymmetric activity coefficient is expressed by the following activity coefficient model:

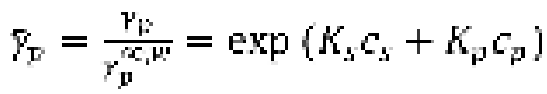

where $K_{s}$ and $K_{p}$ are interaction constants. $K_{s}$ is proportional to the difference of intermolecular attractive forces between protein-water and protein-salt, and $K_{p}$ is proportional to the difference of intermolecular attractive forces between protein-water and protein-protein [10]. 
Combining Equations 2 and 3 yields the single component adsorption isotherm:

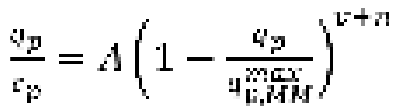

where $A$ is the initial slope of the isotherm or the partition coefficient in the limit $\mathrm{q}_{\mathrm{p}} \rightarrow 0$.

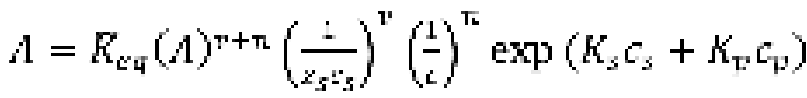

In previous studies of resin columns [13-15], the parameter A was estimated from isocratic retention data under varying salt concentrations. This method is based upon Ettre's definition of the retention factor [16], which considers that part of the solute retention time is due to pore diffusion within the resin beads. This method is limited to the estimation of A for salts that can be used as elution modulators. However, in the case of our MMM adsorbers, not all salt types can be used as elution modulators, and convection dominates the mass transport of protein within the MMM. To overcome this limitation, we used the Langmuir isotherm model to estimate parameter A:

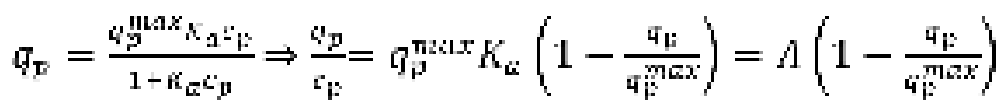

where A represents the initial slope of the isotherm.

Ottens and coworkers provide a detailed account of their methods to fit the isotherm parameters, which include linear regression and constrained minimization [14]. Here, however, we used minimization algorithms from the pyOpt 1.1.0 optimization tool to estimate the parameters providing the best fit of the models to the data [17].

\section{Experimental}

\subsection{Materials}


In our experiments we used regenerated cellulose membranes with a $1.0 \mu \mathrm{m}$ average effective pore size, a $70 \mu \mathrm{m}$ thickness and a $47 \mathrm{~mm}$ diameter, which we purchased from Whatman, Inc. The following chemicals were purchased from Sigma-Aldrich with purities given in weight percentage: 2-bromoisobutyryl bromide (2-BiB, 98\%), copper(I) chloride $(\mathrm{CuCl}, 99.99 \%)$, glycidyl methacrylate (GMA, 97\%), guanidine hydrochloride (Gua-HCl, $\geq 99.9 \%$ ), hydrochloric acid (HCl, 37\%), hydrochloric acid 0.01 M standard solution, 4-mercaptobenzoic acid (99\%), N,N,N',N",N"-pentamethyldiethyldiethylenetriamine (PMDETA, 99\%), phenolphthalein (0.5\% solution), sodium chloride $(\mathrm{NaCl}, \geq 99 \%)$, sodium citrate $(\geq 99 \%)$, sodium hydroxide $0.01 \mathrm{M}$ standard solution, sodium thiocyanate $(\mathrm{NaSCN}, \geq 98 \%$ ), tetrahydrofuran (THF, anhydrous, $\geq 99.9 \%$ ), urea ( $\geq 98 \%$ ). The following chemicals were obtained from Fisher Scientific with purities reported in weight percentage: methanol (99.9\%), phosphate buffered saline (PBS) 1X powder concentrate (Biotech Grade), sodium hydroxide (97\%), tetrahydrofuran (THF, 99\%), trisodium citrate dihydrate $(99 \%)$.

Three buffers were used in the protein dynamic binding experiments. A stock solution of $25 \mathrm{mM}$ PBS was prepared using deionized water from a Milli-Q water purification system (EMD Millipore). The $\mathrm{pH}$ of this PBS buffer was adjusted with $\mathrm{HCl}$ to 6.5 and used as the binding buffer (B). The elution buffer (E1) for dynamic binding experiments was prepared by adding $1 \mathrm{M}$ sodium thiocyanate into $25 \mathrm{mM}$ PBS buffer without $\mathrm{pH}$ adjustment. The regeneration solution (E2) was $6 \mathrm{M}$ Gua- $\mathrm{HCl}$ in water.

\subsection{Membrane surface modification}

The new multimodal membranes were prepared using the surface-initiated ATRP technique, as 
detailed in our previous publication [10]. We first modified regenerated cellulose membranes via surface-initiated ATRP of poly(glycidyl methacrylate) 'tentacles'. Next, an epoxide ring-opening reaction was used to couple 4-mercaptobenzoic acid to the membranes. The details of reaction conditions and times were described previously [10].

\subsection{Ligand density measurement}

A colorimetric titration method was used to determine the ligand density. Specifically, the carboxylate groups on the MMMs were protonated via immersion of a known volume of MMMs in $10 \mathrm{~mL}\left(V_{H C l}\right)$ of standardized $0.01 \mathrm{M}\left(c_{0}\right)$ hydrochloric acid solution, and incubated in a shaker bath $\left(22^{\circ} \mathrm{C}, 100 \mathrm{rpm}\right)$ for $30 \mathrm{~min}$. They were then removed from the hydrochloric acid solution, which was titrated with a standardized $0.01 \mathrm{M}$ sodium hydroxide solution $\left(V_{\mathrm{NaOH}}\right)$. Equation (7) was used to determine the ligand density:

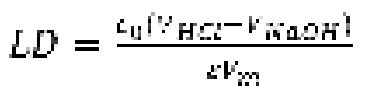

where $\varepsilon$ is the porosity of the MMM and $\mathrm{V}_{\mathrm{m}}$ is its volume (for a single piece of $18 \mathrm{~mm}$-diameter membrane, $\varepsilon=0.8$ and $\mathrm{V}_{\mathrm{m}}$ is $0.018 \mathrm{~mL}$ ).

\subsection{Roles of salt type and ionic strength on IgG adsorption isotherms}

Immunoglobulin $\mathrm{G}(\mathrm{IgG})$ from bovine serum was used to measure equilibrium binding capacities of MMMs. We used three salts to determine their effects on IgG adsorption isotherms: sodium citrate, sodium chloride and sodium thiocyanate (representatives of kosmotropic, 'neutral' and chaotropic salts). Specifically, $25 \mathrm{mM}$ PBS buffers with different concentrations of each salt type and $\mathrm{IgG}$ were prepared, and $\mathrm{HCl}$ was used to adjust the $\mathrm{pH}$ of each solution to 6.5. The multimodal membranes cut into $18 \mathrm{~mm}$-diameter discs were preconditioned with $25 \mathrm{mM}$ PBS 
buffer at a $\mathrm{pH}$ of 6.5 and then rinsed with methanol and dried with nitrogen gas.

Twenty-four MMM samples were used to measure IgG isotherms for each salt type. Isotherms (each composed of six datum points) were measured at four salt concentrations $(0 \mathrm{M}, 0.15 \mathrm{M}, 0.3$

M, $0.45 \mathrm{M}$ ). Protein binding capacities were obtained by contacting $2 \mathrm{~mL}$ of protein solution at defined initial concentrations with one $18 \mathrm{~mm}$-diameter membrane in $20 \mathrm{ml}$ glass vials and measuring the protein concentration in the liquid phase after equilibrium had been reached. Six initial protein concentrations ranging from 0.5 to $5 \mathrm{mg} \mathrm{IgG/ml} \mathrm{were} \mathrm{used} \mathrm{to} \mathrm{obtain} \mathrm{complete}$ adsorption isotherms. The vials were agitated in a shaker bath $\left(22^{\circ} \mathrm{C}, 100 \mathrm{rpm}\right)$ for $20 \mathrm{~h}$. A Cary 50 Bio UV-vis spectrophotometer was used to measure $\mathrm{IgG}$ concentrations at $280 \mathrm{~nm}$. The binding capacities, reported as the adsorbed mass of protein per unit dry volume of membrane, were calculated by mass balance with the initial and final concentrations of protein solution derived from a calibration curve. The membranes were regenerated with $1 \mathrm{M}$ NaSCN solution for reuse.

\subsection{Elution studies}

The MMMs were loaded with $3 \mathrm{mg} \mathrm{IgG} / \mathrm{ml}$ solution at $\mathrm{pH}=6.5$ via equilibrium binding experiments as described in Section 3.4. After loading, the MMMs were immersed in binding buffer B and agitated in a shaker bath $\left(22^{\circ} \mathrm{C}, 100 \mathrm{rpm}\right)$ for $10 \mathrm{~min}$ to remove any unbound $\mathrm{IgG}$. Subsequently, MMMs were transferred into different elution buffers and UV absorbance at 280 $\mathrm{nm}$ for all elution solutions was recorded at $2 \mathrm{~h}$ and $23 \mathrm{~h}$. Three different elution strategies were investigated. The first set of elution buffers was prepared by adjusting $\mathrm{pH}$ of the binding buffer to values ranging from 3.9 to 9.7 using $\mathrm{HCl}$ or $\mathrm{NaOH}$. The second set of elution buffers was 
prepared by adding 1-3 $\mathrm{M}$ urea in the binding buffer. The third set of elution buffers was prepared by adding $0.5-1.5 \mathrm{M}$ salt $(\mathrm{NaSCN}$ and $\mathrm{NaCl})$ in the binding buffer.

\subsection{Kinetic binding study}

A solution of $3.0 \mathrm{mg} \mathrm{IgG/ml} \mathrm{was} \mathrm{prepared} \mathrm{in} 25 \mathrm{mM}$ PBS buffer with a $\mathrm{pH}$ of 6.5. Each membrane was preconditioned as described in Section 3.4, then placed into a $20 \mathrm{~mL}$ glass vial and contacted with $2 \mathrm{~mL}$ of the protein solution in a shaker bath $\left(22{ }^{\circ} \mathrm{C}, 100 \mathrm{rpm}\right)$ for up to $26 \mathrm{~h}$. The membranes were removed from the protein solution at defined times, and protein concentrations were measured by UV adsorbance at $280 \mathrm{~nm}$. The adsorbed mass was calculated by mass balance as described in Section 3.4.

\subsection{Dynamic protein binding capacity}

An AKTA Purifier 100 system was used to measure the dynamic adsorption capacities of MMMs, which were equilibrated with $25 \mathrm{~mL}$ buffer B for $15 \mathrm{~min}$ at room temperature prior to loading into a membrane chromatography module. A stack of 6 MMMs was placed in a Mustang Coin $^{\circledR}$ module (Pall Corporation) with one piece of $25 \mu \mathrm{m}$ nominal pore diameter filter paper (Whatman 5) placed on each side of the stack. The overall bed volume was $0.136 \mathrm{~mL}$. The bed void volume was determined by injecting $1 \mathrm{M} \mathrm{NaSCN}$ solution into the module with no membranes and with membranes. The volume where the conductivity began to increase was recorded. The difference in these volumes represents the void volume of the membrane bed, which was found to be $0.114 \mathrm{~mL}$. Thus, the bed void fraction was 0.84 slightly higher than the individual MMM void fraction of 0.8. The module was inserted in the AKTA purifier. Except for the specifically noted steps, a flow rate of $1 \mathrm{ml} / \mathrm{min}$ (10 column volumes/min) was used during 
the dynamic binding capacity measurements. Buffer B was used to equilibrate the membrane bed until a stable baseline was observed via UV detection at $280 \mathrm{~nm}$. Eighteen milliliters of protein solution $(3 \mathrm{mg} \mathrm{IgG/mL} \mathrm{in} \mathrm{buffer} \mathrm{B,} \mathrm{prefiltered} \mathrm{with} \mathrm{a} \mathrm{VWR} 0.2 \mu \mathrm{m}$ cellulose acetate syringe filter) was injected at flow rates ranging from 0.1 to $0.5 \mathrm{ml} / \mathrm{min}$ (1 to 5 column volumes/min). Unbound protein was washed from the membrane column with $10 \mathrm{~mL}$ buffer B. Fifteen milliliters of buffer E1 was then pumped through the membrane column. Finally, the membrane was regenerated with $5 \mathrm{~mL}$ of $6 \mathrm{M}$ Gua- $\mathrm{HCl}$ solution. In-line $\mathrm{UV}, \mathrm{pH}$ and conductivity detectors were used to monitor the effluent from the membrane column continuously. A pressure transducer installed in the AKTA system was used to measure the pressure drop across the membrane column. All the data were collected, viewed and analyzed by Unicorn 5.11 software (GE Healthcare, Bio-Sciences).

\subsection{Ionic strength effect on dynamic binding capacity}

The procedure described in Section 3.7 was used to determine how the MMM binding capacities were affected by ionic strength, which was varied by adding $\mathrm{NaCl}$ into binding buffer $\mathrm{B}$. The flow rate during loading was $0.1 \mathrm{ml} / \mathrm{min}$. The binding buffers adjusted to a $\mathrm{pH}$ of 6.5 were prepared with 0,150 , and $300 \mathrm{mM} \mathrm{NaCl}$. The protein solutions ( $3 \mathrm{mg} \mathrm{IgG} / \mathrm{ml})$ were prepared with each of the binding buffers.

\section{Results and Discussion}

\subsection{Multimodal adsorbent comparisons}

Three commercial multimodal resins were used to compare their performances with the new MMM: Capto ${ }^{\mathrm{TM}}$ MMC (2-benzamido-4-mercaptobutanoic acid) and Capto ${ }^{\mathrm{TM}} \mathrm{MMC}$ ImpRes 
from GE Healthcare and MBI HypercelTM (2-mercapto-5-benzimidazolesulforic acid) from Pall Corporation. Fig. 1 depicts the ligand structures of the multimodal materials. Table 1 compares the performance characteristics. The ligand density of the MMM determined by titration was substantially higher than the ligand densities of the resins, as was the resulting protein binding capacity. Both were higher because the surface-initiated ATRP technique creates a 3-

dimensional scaffold comprising a high density of grafted polymer chains with accessible protein binding sites. As noted in Table 1, the load productivity for the MMM is also higher than the maximum load productivity for resins, indicating that the MMM column is able to process a larger volume of feed solution in a defined timeframe. The reported load productivity for the MMM is the value measured at the highest flow rate that was studied. Thus, it is a conservative estimate of the achievable productivity. The load productivity advantage originates from the rapid mass transport of the protein molecules from the solution to the binding sites by convective flow within the macropores of MMM [18]. Table 1 also compares the residence times for the MMM and Capto ${ }^{\mathrm{TM}}$ MMC ImpRes at equivalent DBC. The residence time for the MMM is an order of magnitude lower than the resin under conditions that yield the same DBC. This result is important because lower residence times improve productivity and protein product quality. Finally, Table 1 shows that the MMM maintains high capacity under salt conditions where the resin products fail.

\subsection{Salt effect on adsorption isotherms for the MMM}

Salt type and salt concentration are two important factors that influence protein adsorption on multimodal chromatographic adsorbents. Previously, we found that the MMMs exhibit excellent salt tolerance (i.e., maintain high protein binding capacity in the presence of sodium chloride), 
resulting from the combination of Coulombic and hydrophobic interactions [10]. In this study, IgG adsorption isotherms were measured with three different types of salts at four different ionic strengths of practical relevance (Fig.2).

Fig. 2a shows the results using sodium citrate, a kosmotropic salt that can promote hydrophobic interactions between protein molecules and the MMM. As ionic strength increased from 0 to 450 $\mathrm{mM}$, the maximum binding capacity decreased from $177 \mathrm{mg} / \mathrm{ml}$ to $150 \mathrm{mg} / \mathrm{ml}$. There appears to be a minimum in capacity at an intermediate ionic strength of $300 \mathrm{mM}$; however, at the $95 \%$ confidence interval the data for $300 \mathrm{mM}$ and $450 \mathrm{mM}$ are not different. These data can be explained by considering that Coulombic protein-ligand interactions predominate at low salt concentrations and become less important at high ionic strength due to charge screening effects. Kosmotropic salts can enhance hydrophobic interactions; thus, increasing sodium citrate concentration leads to stronger hydrophobic protein-ligand interactions. Because of the opposite trends in Coulombic and hydrophobic interactions with ionic strength, it is reasonable to expect that there is some intermediate salt concentration at which a minimum protein binding occurs.

Sodium thiocyanate, which is a strong chaotropic salt, diminishes hydrophobic interactions while simultaneously disrupting Coulombic interactions by charge screening. Fig. $2 \mathrm{c}$ shows that the IgG binding capacity decreased by nearly $66 \%$, from $177 \mathrm{mg} / \mathrm{ml}$ to $61 \mathrm{mg} / \mathrm{ml}$, as ionic strength increased from 0 to $450 \mathrm{mM}$. Fig. $2 \mathrm{~b}$ shows that a moderate effect of ionic strength on protein binding was observed for sodium chloride (neither a kosmotrope or a chaotrope), with a $40 \%$ decrease in IgG binding capacity from the lowest to the highest ionic strength. 
A general finding is that, relative to traditional ion-exchange media [19], the MMM maintains very high protein binding capacities in the presence of salt at ionic strength values that are typical for elution buffers used in multi-stage antibody purification process. For sodium citrate, a conventional salt used at $150-300 \mathrm{mM}$ ionic strength in elution buffers of Protein A columns, the results indicate that the MMMs are a better choice than traditional cation-exchange materials following the Protein A purification step in the downstream processing of antibody products.

The experimental adsorption isotherm data were fit with Langmuir adsorption model. In Fig. 2d, the association coefficient $K$ (and the parameter describing maximum capacity, $q_{\max }$ ) decreases from kosmotropic to chaotropic salts for reasons explained above. While the Langmuir model described these constant-pH isotherm data well, there is no clear correlation to describe how $K$ (or $q_{\max }$ ) changes with ionic strength. Thus, the Langmuir model is ill-suited for predicting the adsorption behavior under non-test salt conditions.

\subsection{Thermodynamic modeling applied on the MMM}

The thermodynamic model introduced in Section 2 was used to describe experimental data for the IgG adsorption isotherms on MMM (Fig. 3), and a unique set of physically meaningful parameters was regressed to describe binding for all test conditions using a specific salt type (Table 2). Unlike parameters in the Langmuir model, these parameters are independent of ionic strength.

Using the globally regressed parameters, the model correctly describes how IgG binding capacity decreases with increasing salt concentration in all these cases, except for sodium citrate (Fig. 3a). 
While it is clear that Coulombic interactions play an important role for the $\mathrm{NaCl}$ and $\mathrm{NaSCN}$ systems, a close examination of the isotherm parameters in Table 2 shows that both $\mathrm{v}$ and $\mathrm{n}$ are non-zero in all cases, indicating the occurrence of both Coulombic and hydrophobic interactions between IgG and the MMM in all systems. The model-derived isotherms for the sodium citrate system show almost no dependence on ionic strength over the range of conditions studied. However, it does predict a minimum binding capacity occurring at an ionic strength of $0.34 \mathrm{M}$, which is consistent with the apparent minimum seen experimentally at $0.30 \mathrm{M}$. While different salt types clearly contribute to different protein-ligand adsorption stoichiometries, as indicated in Table 2, no correlation was observed between the salt type (i.e., position in the Hofmeister series) and the number of hydrophobic ligands $(n)$, the number of exchangeable counter salt ions (v) and the equilibrium constant $\left(K_{e q}\right)$.

The model-derived maximum binding capacities, also presented in Table 2, are nearly the same for all three salt types. This result is logical because the multimodal ligands have the same

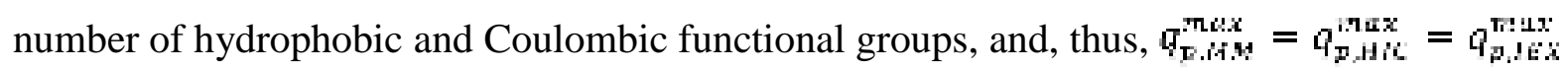
regardless of the interaction type that predominates. Therefore, unlike the $q_{\max }$ parameter in the Langmuir adsorption model, which provides a different apparent binding capacity at each salt condition (type and ionic strength), the $q_{\max }$ provided by the thermodynamic model is independent of both the type and concentration of the salt, and represents the true maximum protein binding capacity of the MMM.

The model parameter $K_{s}$ is proportional to the difference of intermolecular attractive forces between protein-water and protein-salt, and $K_{s}$ is proportional to the difference of intermolecular 
attractive forces between protein-water and protein-protein [10]. The results presented in Table 2 clearly show that water-protein interactions are stronger than protein-protein interactions $\left(K_{p}>\right.$ 0) in the presence of $\mathrm{NaSCN}$, indicating that the chaotropic salt may help to reduce protein aggregates, e.g., in an elution process using this salt. $\mathrm{NaCl}$ and $\mathrm{NaSCN}$ are characterized by a predominance of Coulombic interactions, in which $K_{s}<0$, implying that the salt-protein interactions are stronger than water-protein interactions. In contrast, sodium citrate promotes hydrophobic interactions and is described by $K_{s}>0$, which implies stronger water-protein interactions. Our results substantiate the thinking that $K_{s}<0$ describes systems where Coulombic interactions outweigh hydrophobic interactions, with the reverse true for $K_{s}>0$ [14].

We also used the thermodynamic model to predict an isotherm for a set of non-test conditions. Fig. 2d shows the close correspondence of our predicted isotherm with the experimental data, clearly indicating the efficacy of the thermodynamic model for describing the adsorption process through a set of physically meaningful parameters, and for predicting the adsorption behavior under non-test conditions.

\subsection{Elution method investigation}

The selection of the elution method for multimodal adsorbers is more complicated than the selection for traditional ion-exchange and hydrophobic interaction chromatography media. This complexity is due to the occurrence of multiple interaction types between multimodal functional groups and target molecules, and the strength of these individual interactions, which varies with changes in the process conditions. Therefore, the interactions of IgG with the MMM were modulated with different salts and additives to identify an effective elution strategy for 
recovering $\mathrm{IgG}$ from the MMM adsorbents.

Fig. 4a shows the effect of solution $\mathrm{pH}$ on IgG recovery. The isoelectric point of $\mathrm{IgG}$ is in the range 6.5-7.5, while the $p K_{a}$ value for the carboxylic acid group on 4-mercaptobenzoic acid is 4.80; although, we caution that it is not uncommon for the acidity constant of a polymeric organic acid to be different from its corresponding monomer value due to the change of chemical environment in the polymer [20]. For all $\mathrm{pH}$ values above 7.5 , the recovery percentages increased with increasing $\mathrm{pH}$. This result is consistent with the fact that both the MMM and $\operatorname{IgG}$ are charged negatively and that the magnitude of the $\mathrm{IgG}$ charge increases with increasing $\mathrm{pH}$ above $\mathrm{pI}$. Hydrophobic interactions are independent of the $\mathrm{pH}$, and contribute to $\mathrm{IgG}$ binding capacity at high $\mathrm{pH}$. No significant elution was observed for $\mathrm{pH}$ levels below 5.0. The acid groups of the MMM are protonated at lower $\mathrm{pH}$ and allow hydrogen bonding to occur between the MMM and IgG.

With evidence that the MMM can associate with IgG through hydrogen bonding, urea, a hydrogen bond disruptor, was expected to affect the strength of IgG interactions with the MMM. As demonstrated in Fig. 4b, the percentage recovery increased by increasing the concentration of urea in the elution buffer.

As described in detail earlier, salt type and concentration affect protein-ligand interactions. Fig. $4 \mathrm{c}$ shows the percentage recovery for $\mathrm{NaCl}$ used as an elution salt, in which a $23 \mathrm{~h}$ elution yields a percentage recovery that is twice as high as that for a $2 \mathrm{~h}$ elution. This result indicates that $\mathrm{NaCl}$ would not be an effective salt for elution, as a slow elution mechanism would yield a broad 
peak and, thus, low resolution separations in the dynamic elution process. From the lowest $(0.5 \mathrm{M})$ to highest $(1.5 \mathrm{M}) \mathrm{NaCl}$ concentration, the recovery percentage at $23 \mathrm{~h}$ increases only $~$ $12 \%$. This elution strategy is inefficient; the presence of hydrophobic interactions can compensate for a partial loss in binding capacity caused by disruption of Coulombic interactions. In this case, the excellent salt tolerance of the MMM is a disadvantage.

The use of a chaotropic salt such as NaSCN in an elution method can interrupt both the Coulombic and hydrophobic interactions. Fig. 4d supports this idea, as elution with $0.5 \mathrm{M}$ $\mathrm{NaSCN}$ yielded a high recovery percentage ( 84\%) within $2 \mathrm{~h}$. Increasing the NaSCN concentration to $1.0 \mathrm{M}$ yielded a $100 \%$ recovery percentage after $2 \mathrm{~h}$. This result satisfied our objective to identify an effective elution strategy for fully recovering IgG from the MMM adsorbers in a short time. This strategy was used to regenerate MMM columns in the breakthrough studies described later.

The elution strategies investigated here provide an excellent roadmap for future work using MMMs for bind-and-elute chromatography. Before MMM chromatography can be of practical industrial use, comprehensive studies involving other elution modulators and gradient elution strategies to separate multicomponent mixtures must be undertaken. These studies are underway in our lab.

\subsection{Kinetic binding study}

A kinetic binding study was conducted to determine the rate of adsorption of IgG on the MMM discussed in this paper. Fig. 5 shows the rate of uptake measured by batch-type static binding 
capacity experiments, where each symbol represents the average static binding capacity results of two measurements.

Although the results in Fig. 5 indicate an overall high binding capacity, they also show relatively slow IgG binding kinetics. This may limit the achievable load productivity of the MMM in a bind-and-elute chromatography process. It has been established that mass transport of proteins in macroporous membranes modified using the surface-initiated ATRP technique is governed by convection, rather than diffusion (a major improvement over resin beds). For purposes of determining if the rate limiting step for the chromatography process is convective flow or the protein-ligand adsorption reaction, we used Equation 8 to calculate the Damköhler number (Da):

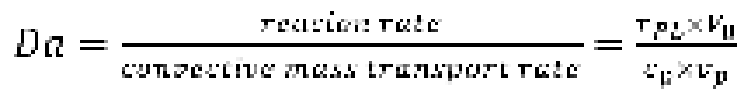

where $r_{P L}$ is the rate of protein adsorption on the MMM, $V_{0}$ is the MMM bed volume used in this study; $c_{p}$ is the feed protein concentration; and $v_{p}$ is the flowrate.

The protein-ligand adsorption reaction rate was estimated by linear regression of data in Fig. 5 over the first $2 \mathrm{~h}$. The initial slope yields a reaction rate of $0.63 \mathrm{mg} /(\mathrm{ml} \times \mathrm{min})$. In the MMM chromatography column, the bed volume is $0.1 \mathrm{~mL}$ and a typical feed solution is $3 \mathrm{mg} \mathrm{IgG} / \mathrm{mL}$ flowing at a rate of at $0.1 \mathrm{~mL} / \mathrm{min}$. The estimated value for Da was therefore 0.2 . As a rule of thumb [21], in this continuous-flow MMM column, Da>10 indicates a sufficiently rapid proteinligand reaction rate, in which $90 \%$ of the available protein will adsorb onto the membrane column. However, in our analysis, $\mathrm{Da}<<10$, indicating that the adsorption reaction in this case was the rate limiting step. It is thought that this slow reaction rate might possibly originate from 
the hydrophobicity of the ligands, which affects both the polymer conformation and the number of easily accessible binding sites. Over time as protein binds within the polymer layer, it swells and provides access to additional binding sites, resulting in high equilibrium capacities. However, premature breakthrough will occur if the residence time is insufficient to allow this process to occur.

\subsection{Flow rate effect on MMM column back pressure}

Fig. 6 shows the dependence of the column backpressure on linear flow velocity for MMM columns. Pressures were recorded after a binding buffer was used to equilibrate the column. As expected, we recorded a higher backpressure in the MMM column than in the unmodified membrane column. This result indicates that the multimodal polymer "tentacles" grafted from the pore surfaces reduce the pore sizes. The back pressures of the empty column were measured as a control in this study. At the same linear flow rates, the back pressures for the empty column were $65-100 \%$ of the back pressure for the membrane column, indicating that the membrane module contributed most of the resistance to flow. For example, at a flow rate of $531 \mathrm{~cm} / \mathrm{h}(=10$ $\mathrm{ml} / \mathrm{min}$ ), backpressures for the MMM column and empty column were $0.49 \mathrm{MPa}$ and $0.32 \mathrm{MPa}$.

The data show a linear increase in the pressure with an increase in the linear flow velocity, a relationship anticipated by the Kozeny-Carman equation used to describe the pressure drop of a fluid flowing through a packed bed of solids. In addition, the Kozeny-Carman equation indicates that the pressure drop should increase with an increase in the bed height, which is supported by the experimental results on membrane columns with different bed thickness. 


\subsection{Dynamic protein binding capacities}

To measure the dynamic binding capacities and reusability of the MMM, a bind-and-elute chromatographic operation was used. Due to the presence of both hydrophobic and hydrophilic groups, the multimodal polymer chains adjust their geometric orientation according to buffer flow [10]. Therefore, prior to loading the protein feed, the binding buffer was pumped through the membrane bed to equilibrate the multimodal polymer chains. After equilibration, $\operatorname{IgG}$ solution was injected into the MMM column, and data collection began at the time of injection. In our previous study, we found that the optimum $\mathrm{pH}$ for IgG adsorption on the MMM is around 6.5 , near its isoelectric point. Therefore, in the dynamic binding capacity experiments, we fixed the $\mathrm{pH}$ at 6.5 for both the binding buffer and the injected protein solutions.

After the injection, unbound proteins were washed from the membrane bed using a binding buffer that returned the UV absorbance to the baseline. An isocratic elution strategy was subsequently used to release the adsorbed protein molecules from the membrane column. The elution buffer comprised $1 \mathrm{M} \mathrm{NaSCN}$ in $25 \mathrm{mM}$ PBS buffer. At this condition of high ionic strength, the Coulombic interactions between the membrane bed and the IgG molecules were screened by ions in the elution buffer. Furthermore, the presence of NaSCN, a strong chaotropic salt, also interrupted the hydrophobic interactions between the membrane bed and the proteins, as discussed in Section 4.2. This elution strategy was effective in fully regenerating the membrane column; it was reused more than ten times following the same bind-and-elute protocol, with no subsequent loss in performance. 


\subsubsection{Breakthrough analysis}

To determine the dynamic binding capacities of the MMM, a breakthrough analysis was conducted by monitoring the effluent protein concentration from the AKTA purifier. Fig. 7 illustrates the breakthrough curves for unmodified and MMM membrane beds. We measured the dynamic binding capacities at $10 \%, 50 \%$, and $95 \%$ breakthrough, i.e., where the effluent concentrations reach $10 \%, 50 \%$ and $95 \%$ of the feed concentration. The curve for the unmodified membrane bed was used to define the dead volume of the system.

Table 3 summarizes the DBC results. As expected, the $\mathrm{SBC}$ of $127 \mathrm{mg} / \mathrm{ml}$ measured in batch uptake experiments was slightly higher than the $118 \mathrm{mg} / \mathrm{ml} \mathrm{DBC}_{95 \%}$. The capacity at $10 \%$ breakthrough, $\mathrm{DBC}_{10 \%}$, was $56 \mathrm{mg} / \mathrm{mL}$ As discussed in Section 4.5, slow binding kinetics contribute to $\mathrm{DBC}_{10 \%}$ being much lower than $\mathrm{SBC}$. The load productivity at $10 \%$ breakthrough was $10.2 \mathrm{mg} /(\mathrm{ml} \times \mathrm{min})$, calculated according to the equation developed in prior research by our group [22]. These results indicate that the new MMM has a sufficiently high binding capacity for industrial application, with a high productivity relative to commercial products. There may be room for improvement in load productivity by increasing flow rate; although, the achievable flow rate will be limited by the protein-ligand reaction rate.

Although it is standard practice to report dynamic capacity at 10\% breakthrough, Table 3 also presents values for $\mathrm{DBC}_{50 \%}$ and $\mathrm{DBC}_{95 \%}$. These values may be useful to evaluate the potential of the MMM for overload and elute purification of antibodies, a technique described by Nadarajah and Mehta [23]. 


\subsubsection{Flow rate effect on dynamic binding capacity}

The MMM column was examined under three different flow rates, the dynamic binding capacity and productivity results of which are presented in Table 4 . A five-fold increase in the flow rate decreased $\mathrm{DBC}_{10 \%}$ by only $9 \%$. Despite the minor effect on binding capacity, this increase in flow rate dramatically increased the load productivity by 4.9 times. Under these test conditions, the MMM column had a productivity of nearly $11.7 \mathrm{mg} /(\mathrm{mL} \times \mathrm{min})$, twice as high as the maximum load productivity for current multimodal resin products (Table 1). Increasing process productivity is beneficial to the quality of the protein products, as long purification time is detrimental to both the stability and activity of proteins $[24,25]$.

\subsubsection{Ionic strength effect on dynamic binding capacity}

Table 4 also summarizes the effect of ionic strength on protein dynamic binding capacity of the MMM column. Compared to the dynamic binding capacity of $47 \mathrm{mg} \mathrm{IgG/ml} \mathrm{at} 0 \mathrm{mM} \mathrm{NaCl}$ in 25 mM PBS buffer, the MMM bed retained $81 \%$ and $70 \%$ of the binding capacity at $150 \mathrm{mM}$ and $300 \mathrm{mM} \mathrm{NaCl}$ in $25 \mathrm{mM}$ PBS buffer. Results from dynamic capacity measurements validate our previous claim based on equilibrium measurements that the MMM has excellent salt tolerance [10]. The ability of the MMM to bind protein under conditions of high ionic strength may eliminate the need for feedstock conditioning (e.g., desalting or dilution) to optimize loading following a Protein A capture step. Decreasing the number of steps would be particularly useful for improving the downstream purification process of therapeutic proteins, which are sensitive to processing times.

The MMM prepared in this study is being evaluated as a less expensive alternative to Protein A 
chromatography. Protein A resins cost almost an order of magnitude more than non-affinity media [26]. Thus, processes that replace Protein A chromatography with ion exchange and hydrophobic interaction chromatography $[27,28]$ could reduce purification costs significantly. Studies along these lines with our MMM are under way and will be published in the future.

\section{Conclusions}

Our newly designed multimodal membrane (MMM) is characterized by high protein binding capacities and high load productivity. IgG equilibrium binding capacity was insensitive to sodium citrate concentration over the range of concentrations used in elution buffers of Protein A columns, which indicates that the elution pool from Protein A chromatography could be loaded directly on the MMM without desalting.

A thermodynamic model was used to provide insights on the nature of protein-MMM interactions and to predict binding capacities under non-test conditions, which is important for limiting the number of experiments needed for process development.

It also was determined that the rate limiting step of $\mathrm{IgG}$ adsorption on the MMM is the reaction rate of IgG binding with the multimodal ligands, rather than the mass transport of protein molecules. Thus, while high load productivities were achieved, improvements in membrane design leading to faster adsorption kinetics would enable still higher productivities.

Taken together, the results of this study strengthen the argument that multimodal membrane bind-and-elute chromatography can be a highly productive and scalable process. The ability to 
work at high salt concentrations may reduce the number of steps in the protein purification train, improving product quality, enhancing manufacturing capacity in existing facilities, and reducing the cost of downstream purification. To facilitate membrane chromatography process development, research is needed to develop a model framework to predict breakthrough curves on MMM column. Investigations also are needed to test the newly designed membranes for recovery of proteins from complex bioprocess streams. These studies are under way in our lab and will be published in the future.

\section{Acknowledgement}

We wish to acknowledge the National Science Foundation for financial support under NSF award CBET-1159622.

\section{References}

[1] R.K. Scopes, Protein purification: principles and practice, , Springer, 1994.

[2] A.A. Shukla, B. Hubbard, T. Tressel, S. Guhan, and D. Low. Downstream processing of monoclonal antibodies - application of platform approaches. Journal of Chromatography B, 848 (2007) 28.

[3] M. Toueille, A. Uzel, J. Depoisier, and R. Gantier. Designing new monoclonal antibody purification processes using mixed-mode chromatography sorbents. Journal of Chromatography B, 879 (2011) 836.

[4] J. Chen, J. Tetrault, Y. Zhang, A. Wasserman, G. Conley, M. DiLeo, et al. The distinctive separation attributes of mixed-mode resins and their application in monoclonal antibody downstream purification process. Journal of Chromatography A, 1217 (2010) 216.

[5] J. Pezzini, G. Joucla, R. Gantier, M. Toueille, A. Lomenech, C. Le Sénéchal, et al. Antibody capture by mixed-mode chromatography: A comprehensive study from determination of optimal purification conditions to identification of contaminating host cell proteins. Journal of Chromatography A, 1218 (2011) 8197. 
[6] P. Gagnon. Technology trends in antibody purification. Journal of chromatography A, 1221 (2012) 57.

[7] D.J. Roush, Y. Lu. Advances in primary recovery: centrifugation and membrane technology. Biotechnol.Prog., 24 (2008) 488.

[8] A.A. Shukla, J. Thömmes. Recent advances in large-scale production of monoclonal antibodies and related proteins. Trends Biotechnol., 28 (2010) 253.

[9] T.J. Menkhaus, H. Varadaraju, L. Zhang, S. Schneiderman, S. Bjustrom, L. Liu, et al. Electrospun nanofiber membranes surface functionalized with 3-dimensional nanolayers as an innovative adsorption medium with ultra-high capacity and throughput. Chem.Commun., 46 (2010) 3720.

[10] J. Wang, R.T. Sproul, L.S. Anderson, and S.M. Husson. Development of multimodal membrane adsorbers for antibody purification using atom transfer radical polymerization. Polymer, 55 (2014) 1404.

[11] S. Bhattacharjee, J. Dong, Y. Ma, S. Hovde, J.H. Geiger, G.L. Baker, et al. Formation of high-capacity protein-adsorbing membranes through simple adsorption of poly (acrylic acid)containing films at low pH. Langmuir, 28 (2012) 6885.

[12] C.A. Brooks, S.M. Cramer. Steric mass-action ion exchange: displacement profiles and induced salt gradients. AIChE J., 38 (1992) 1969.

[13] J.M. Mollerup. Applied thermodynamics: A new frontier for biotechnology. Fluid Phase Equilib., 241 (2006) 205.

[14] B.K. Nfor, M. Noverraz, S. Chilamkurthi, P.D. Verhaert, van der Wielen, Luuk AM, and M. Ottens. High-throughput isotherm determination and thermodynamic modeling of protein adsorption on mixed mode adsorbents. Journal of Chromatography A, 1217 (2010) 6829.

[15] J.M. Mollerup, T.B. Hansen, S. Kidal, and A. Staby. Quality by design-thermodynamic modelling of chromatographic separation of proteins. Journal of Chromatography A, 1177 (2008) 200.

[16] L. Ettre. Nomenclature for chromatography (IUPAC Recommendations 1993). Pure and applied chemistry, 65 (1993) 819.

[17] R.E. Perez, P.W. Jansen, and J.R. Martins. pyOpt: a Python-based object-oriented framework for nonlinear constrained optimization. Structural and Multidisciplinary Optimization, 45 (2012) 101.

[18] B.V. Bhut, S.M. Husson. Dramatic performance improvement of weak anion-exchange membranes for chromatographic bioseparations. J.Membr.Sci., 337 (2009) 215. 
[19] Q. Lan, A.S. Bassi, J.J. Zhu, and A. Margaritis. A modified Langmuir model for the prediction of the effects of ionic strength on the equilibrium characteristics of protein adsorption onto ion exchange/affinity adsorbents. Chem.Eng.J., 81 (2001) 179.

[20] H. Dong, H. Du, and X. Qian. Theoretical Prediction of p K a Values for Methacrylic Acid Oligomers Using Combined Quantum Mechanical and Continuum Solvation Methods. The Journal of Physical Chemistry A, 112 (2008) 12687.

[21] H. Fogler, Elements of Chemical Reaction Engineering, , Prentice Hall, 2005.

[22] H. Chenette, J.R. Robinson, E. Hobley, and S.M. Husson. Development of high-productivity, strong cation-exchange adsorbers for protein capture by graft polymerization from membranes with different pore sizes. J.Membr.Sci., 423-424 (2012) 43.

[23] D. Nadarajah, A. Mehta. Overload and elute chromatography, (2012).

[24] G.E. Hamilton, F. Luechau, S.C. Burton, and A. Lyddiatt. Development of a mixed mode adsorption process for the direct product sequestration of an extracellular protease from microbial batch cultures. J.Biotechnol., 79 (2000) 103.

[25] K.A. Kaleas, C.H. Schmelzer, and S.A. Pizarro. Industrial case study: Evaluation of a mixed-mode resin for selective capture of a human growth factor recombinantly expressed in $<\mathrm{i}>$ E. coli</i>. Journal of Chromatography A, 1217 (2010) 235.

[26] X. Han, A. Hewig, and G. Vedantham, Chapter 14: Recovery and Purification of Antibody, in M. Al-Rubeai (Ed.), Antibody Expression and Production, New York, Springer Verlag, 2011.

[27] D.K. Follman, R.L. Fahrner. Factorial screening of antibody purification processes using three chromatography steps without protein A. Journal of Chromatography A, 1024 (2004) 79.

[28] J.K. Grzeskowiak, A. Tscheliessnig, P.C. Toh, J. Chusainow, Y.Y. Lee, N. Wong, et al. Two-dimensional fluorescence difference gel electrophoresis for comparison of affinity and nonaffinity based downstream processing of recombinant monoclonal antibody. Journal of Chromatography A, 1216 (2009) 4902. 


\section{Figure Captions}

Figure 1. (a) Multimodal Membranes (MMM) developed in our group [7]; (b) MBI Hypercel ${ }^{\mathrm{TM}}$ from Pall Life Science, NY, USA; (c) Capto ${ }^{\mathrm{TM}}$ MMC and Capto ${ }^{\mathrm{TM}}$ MMC ImpRes from GE Healthcare, NJ, USA.

Figure 2. Roles of ionic strength and salt type on adsorption isotherms for $\operatorname{IgG}$ at $22^{\circ} \mathrm{C}$ : (a) sodium citrate, (b) sodium chloride, (c) sodium thiocyanate, (d) Langmuir model association constant. The multimodal membranes were prepared by $21 \mathrm{~h}$ surface-initiated ATRP and 4mercaptobenzoic acid incorporation at $65^{\circ} \mathrm{C}$. Symbols represent experimental data, and curves represent best fits using the Langmuir adsorption model. The error bars in IgG static binding capacities represent the standard deviation of two measurements, while the error bars in association coefficient indicate the standard deviation from nonlinear regression.

Figure 3. Evaluation of multimodal thermodynamic adsorption model for describing IgG adsorption isotherms at $22{ }^{\circ} \mathrm{C}$ : (a) sodium citrate, (b) sodium chloride, (c) sodium thiocyanate, Symbols represent experimental data, and curves represent best fits using the thermodynamic model. (d) Symbols represent experimental data at $75 \mathrm{mM} \mathrm{NaCl}$ with error bars from standard deviations among four repeated measurements. Curve shows the isotherm prediction by the thermodynamic model.

Figure 4. Influence of different elution modulators on IgG recovery from the MMM: (a) pH, (b) urea concentration, (c) $\mathrm{NaCl}$ concentration, (d) NaSCN concentration. 
Figure 5. Batch kinetics of IgG binding to the MMM from a solution of $3 \mathrm{mg} \mathrm{IgG/ml} \mathrm{in} 25 \mathrm{mM}$ PBS buffer at $\mathrm{pH}=6.5$. Contacting was done with agitation at $22^{\circ} \mathrm{C}$. The data represent average binding capacities from two measurements.

Figure 6. Dependence of back pressure on linear flow rate for MMMs (bed height: $140 \mu \mathrm{m}$ for 2 membranes and $350 \mu \mathrm{m}$ for 5 membranes; buffer: $25 \mathrm{mM}$ PBS buffer at $\mathrm{pH}=6.5$; module: CIM $^{\circledR}$ BIA Separations, Inc.).

Figure 7. Breakthrough curves for un-modified membrane and MMM (bed height: $420 \mu \mathrm{m}$; bed diameter: $16 \mathrm{~mm}$; feed solution: $3 \mathrm{mg} \mathrm{IgG} / \mathrm{ml}$; buffer: $25 \mathrm{mM}$ PBS buffer at $\mathrm{pH}=6.5$ ). 

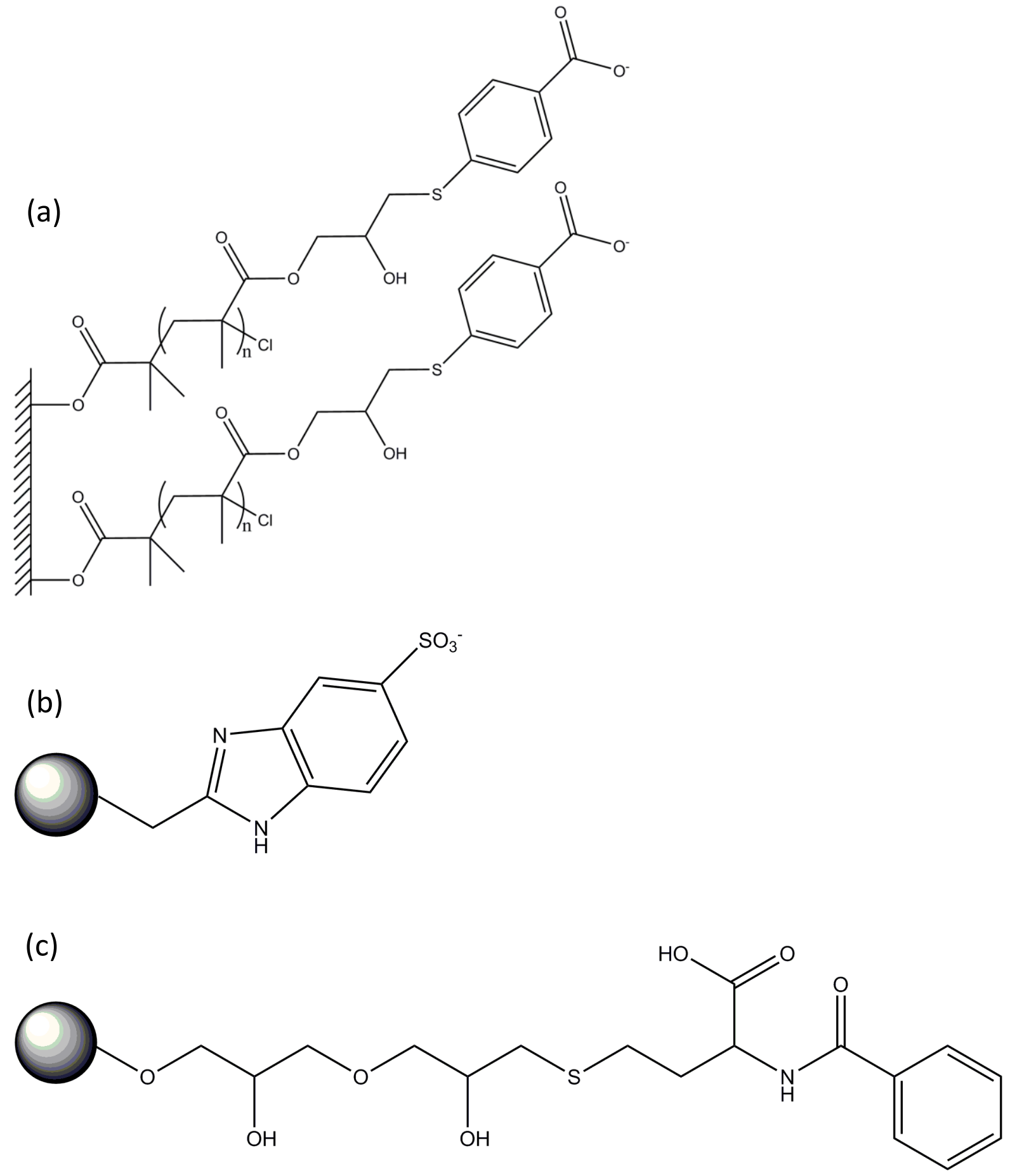

Figure 1. (a) Multimodal Membranes (MMM) developed in our group [7]; (b) MBI Hypercel ${ }^{\mathrm{TM}}$ from Pall Life Science, NY, USA; (c) Capto ${ }^{\mathrm{TM}}$ MMC and Capto ${ }^{\mathrm{TM}}$ MMC ImpRes from GE Healthcare, NJ, USA. 



Figure 2. Roles of ionic strength and salt type on adsorption isotherms for IgG at $22{ }^{\circ} \mathrm{C}$ : (a) sodium citrate, (b) sodium chloride, (c) sodium thiocyanate, (d) Langmuir model association constant. The multimodal membranes were prepared by $21 \mathrm{~h}$ surface-initiated ATRP and 4-mercaptobenzoic acid incorporation at $65{ }^{\circ} \mathrm{C}$. Symbols represent experimental data, and curves represent best fits using the Langmuir adsorption model. The error bars in IgG static binding capacities represent the standard deviation of two measurements, while the error bars in association coefficient indicate the standard deviation from nonlinear regression. 

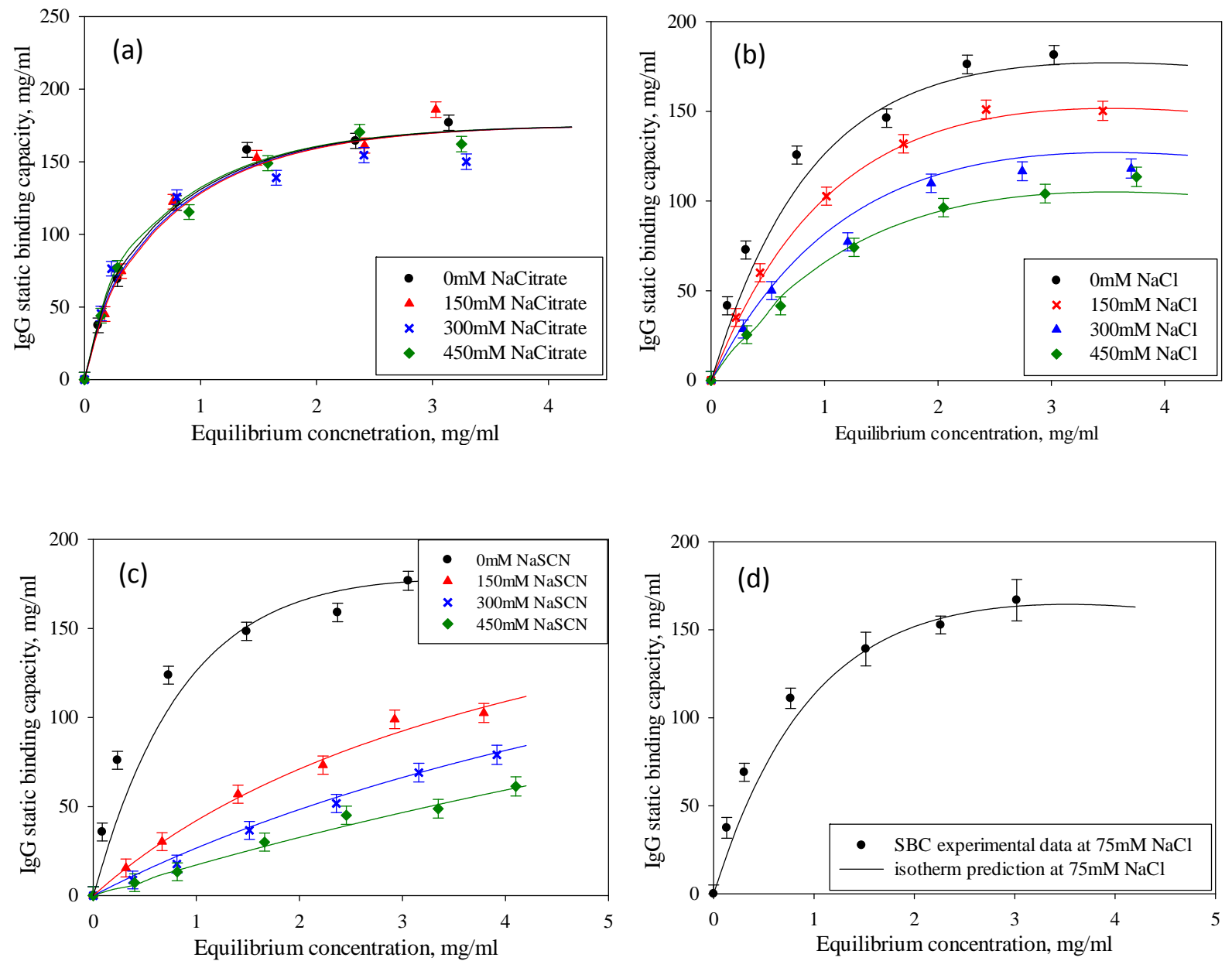

Figure 3. Evaluation of multimodal thermodynamic adsorption model for describing IgG adsorption isotherms at $22^{\circ} \mathrm{C}$ : (a) sodium citrate, (b) sodium chloride, (c) sodium thiocyanate, Symbols represent experimental data, and curves represent best fits using the thermodynamic model. (d) Symbols represent experimental data at $75 \mathrm{mM} \mathrm{NaCl}$ with error bars from standard deviations among four repeated measurements. Curve shows the isotherm prediction by the thermodynamic model. 


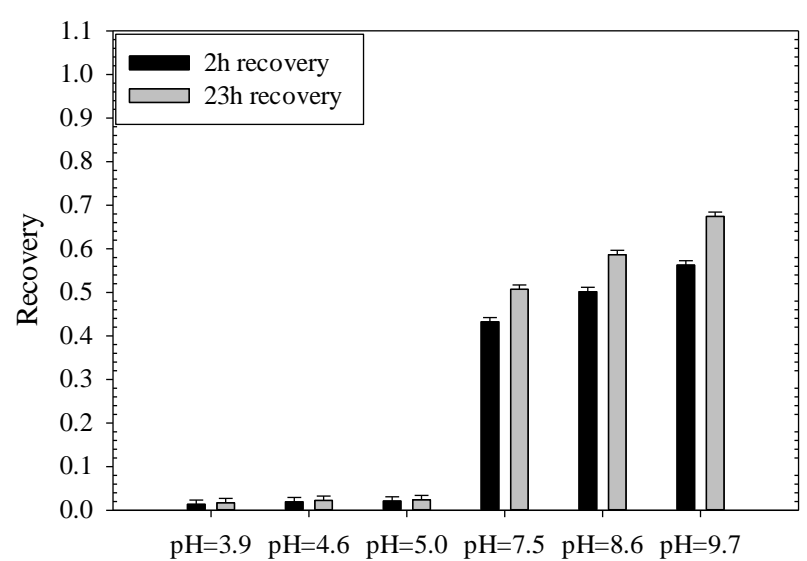

(a)

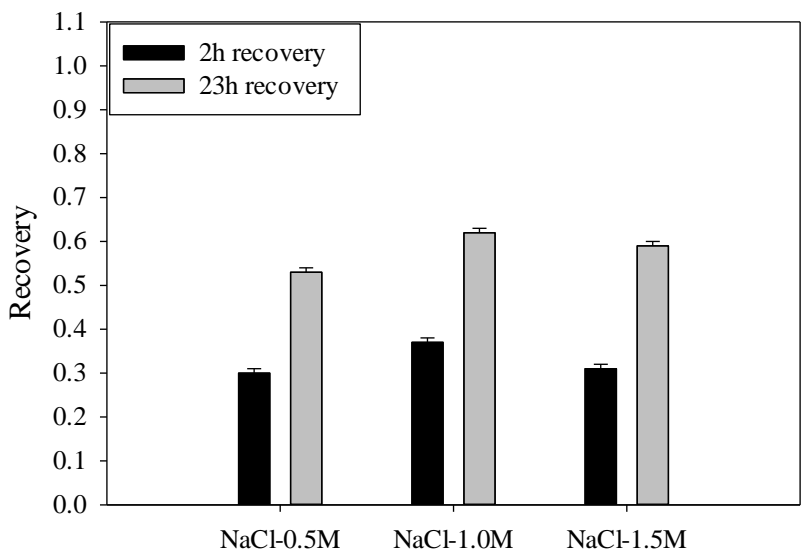

(c)

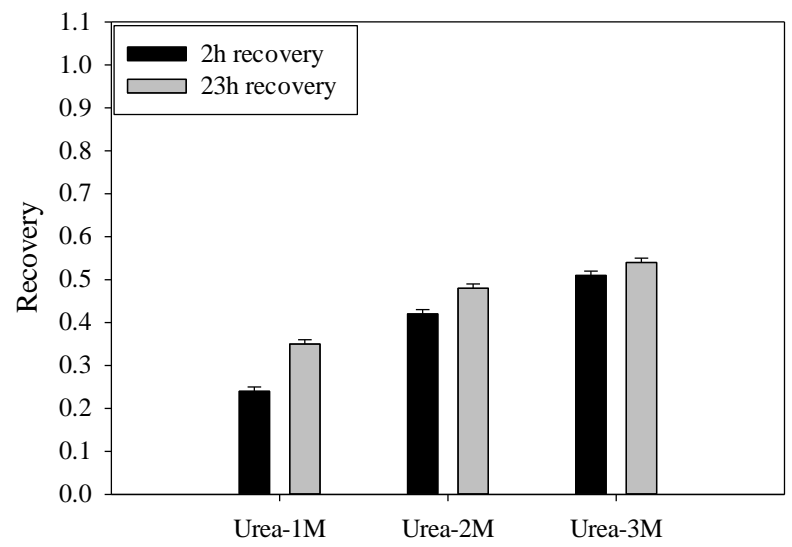

(b)

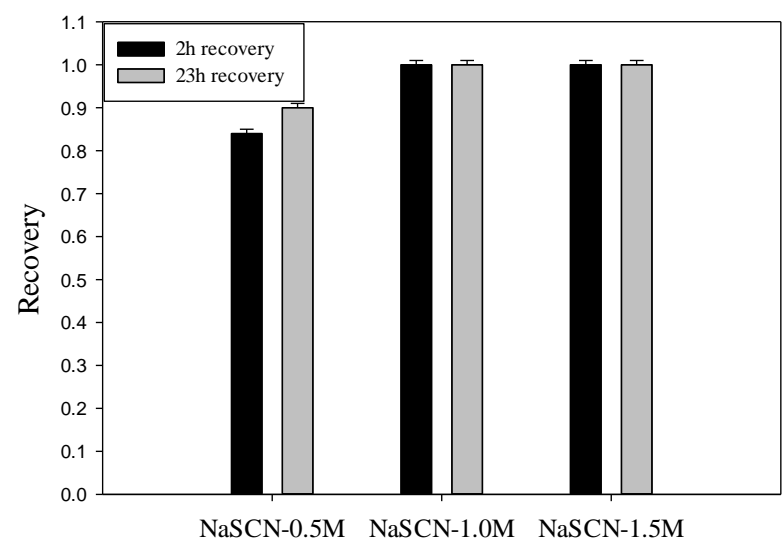

(d)

Figure 4. Influence of different elution modulators on $\mathrm{IgG}$ recovery from the MMM: (a) $\mathrm{pH}$, (b) urea concentration, (c) $\mathrm{NaCl}$ concentration, (d) NaSCN concentration. 


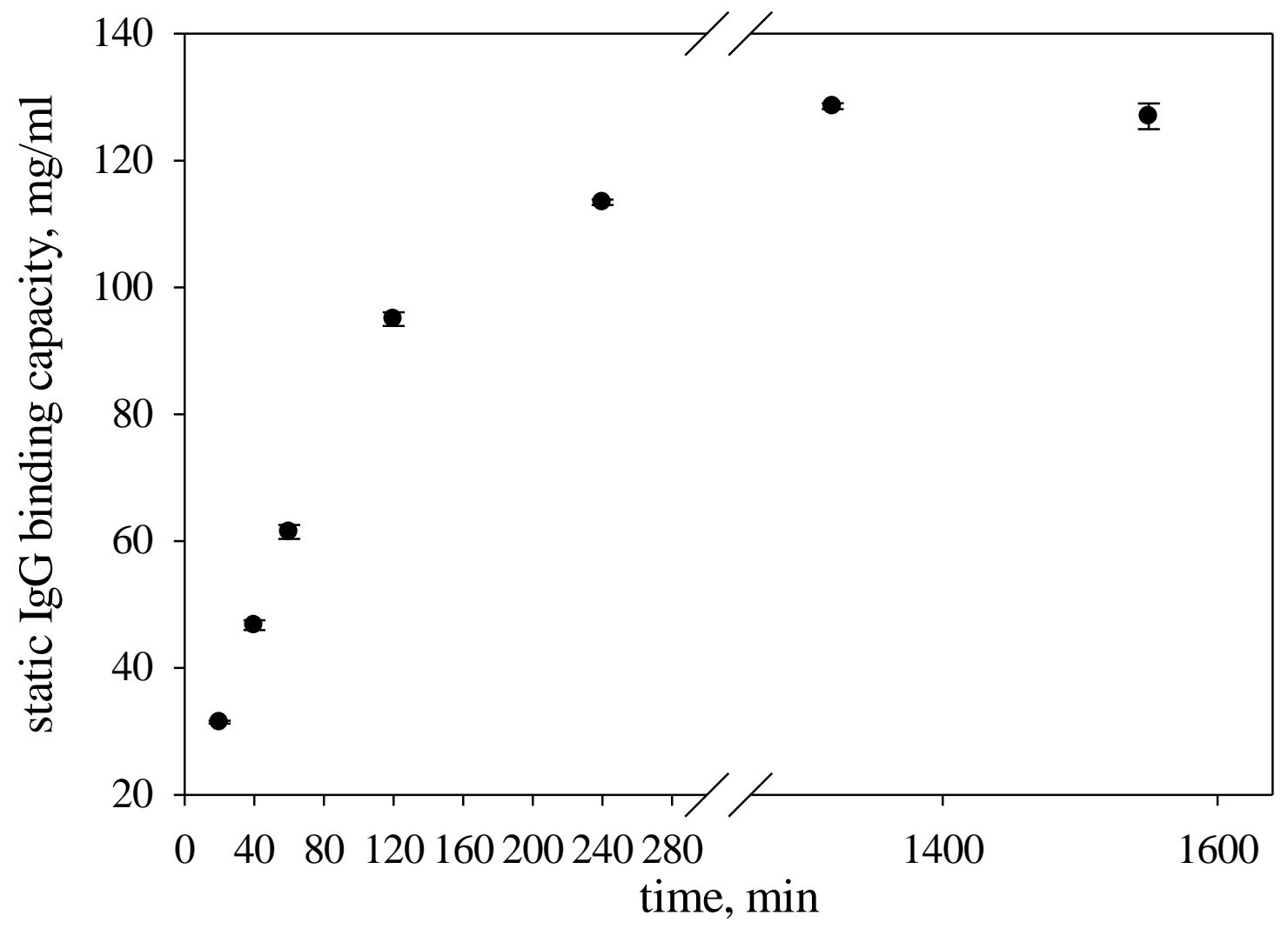

Figure 5. Batch kinetics of IgG binding to the MMM from a solution of $3 \mathrm{mg} I g G / \mathrm{ml}$ in $25 \mathrm{mM}$ PBS buffer at $\mathrm{pH}=6.5$. Contacting was done with agitation at $22{ }^{\circ} \mathrm{C}$. The data represent average binding capacities from two measurements. 


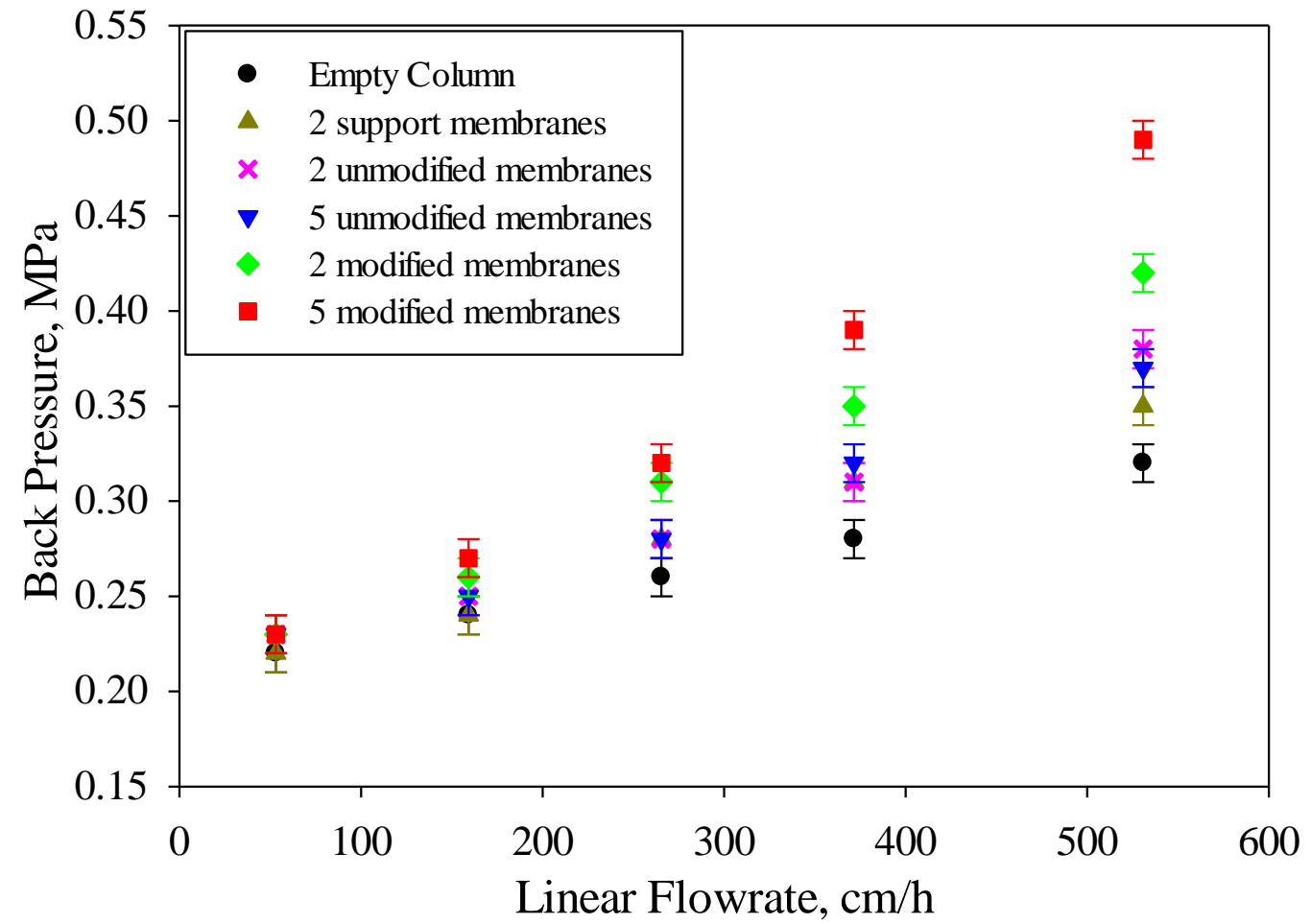

Figure 6. Dependence of back pressure on linear flow rate for MMMs (bed height: $140 \mu \mathrm{m}$ for 2 membranes and $350 \mu \mathrm{m}$ for 5 membranes; buffer: $25 \mathrm{mM}$ PBS buffer at $\mathrm{pH}=6.5$; module: $\mathrm{CIM}^{\circledR} \mathrm{BIA}$ Separations, Inc.). 


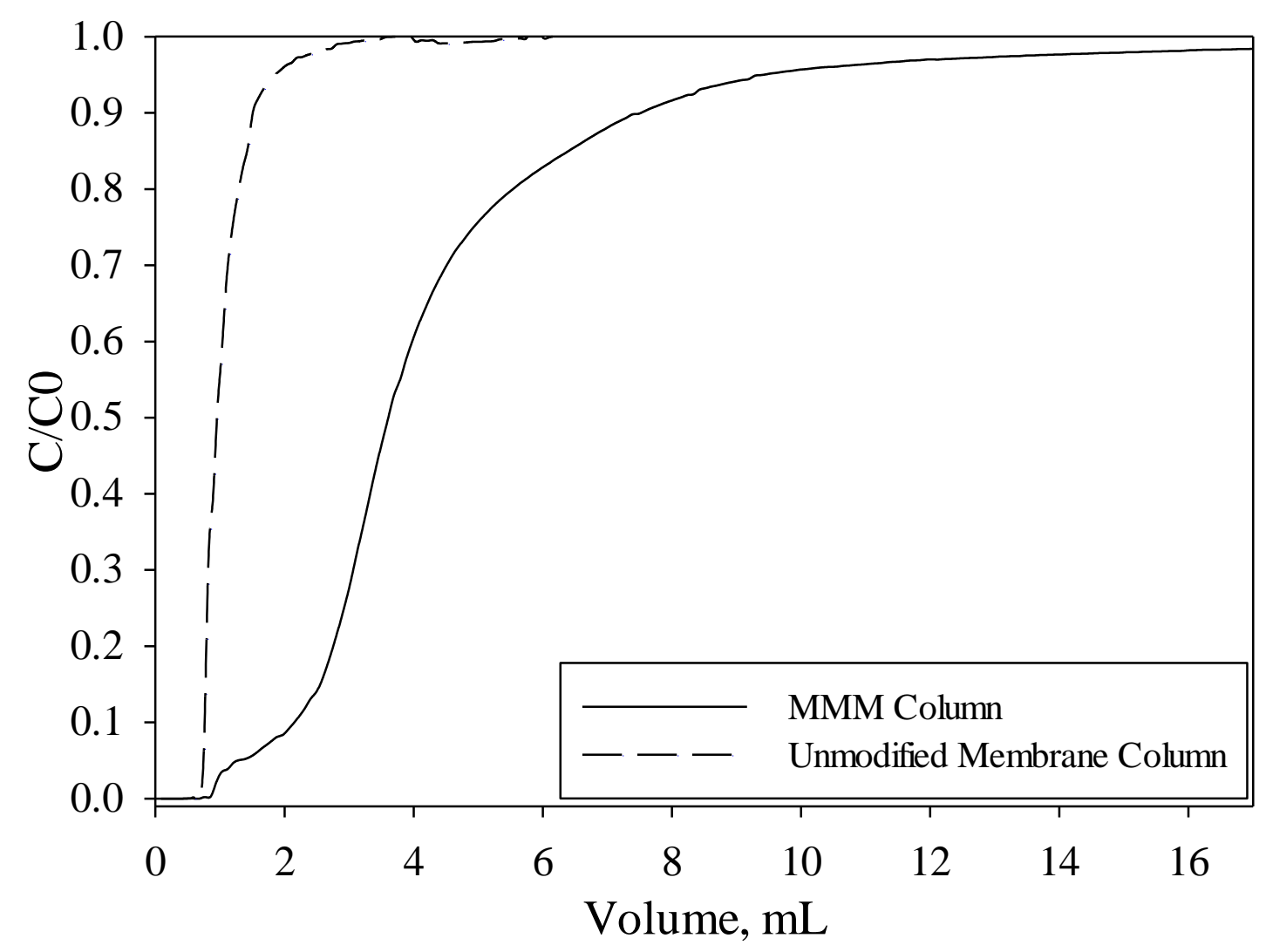

Figure 7. Breakthrough curves for un-modified membrane and MMM (bed height: $420 \mu \mathrm{m}$; bed diameter: $16 \mathrm{~mm}$; feed solution: $3 \mathrm{mg} \mathrm{IgG/ml}$; buffer: $25 \mathrm{mM}$ PBS buffer at $\mathrm{pH}=6.5$ ). 
Table 1. Comparison of performance characteristics of the new MMM and commercial MMC resins.

\begin{tabular}{|c|c|c|c|c|c|c|}
\hline $\begin{array}{c}\text { Chromatography } \\
\text { Medium }\end{array}$ & $\begin{array}{l}\text { Average } \\
\text { Ligand } \\
\text { Density } \\
\text { (mmol/L) }\end{array}$ & $\begin{array}{l}\text { IgG Static } \\
\text { Binding } \\
\text { Capacity } \\
\text { (mg/ml) }\end{array}$ & $\begin{array}{l}\text { IgG Dynamic } \\
\text { Binding } \\
\text { Capacity* } \\
\text { (mg/ml) }\end{array}$ & $\begin{array}{c}\text { Residence } \\
\text { time } \\
\text { (min) }\end{array}$ & $\begin{array}{c}\text { Load } \\
\text { Productivity } \\
\text { (mg/ml/min) }\end{array}$ & $\begin{array}{c}\text { IgG Static } \\
\text { Binding } \\
\text { Capacity at } \\
300 \mathrm{mM} \mathrm{NaCl} \\
(\mathrm{mg} / \mathrm{ml})\end{array}$ \\
\hline MMM & $340 \pm 24$ & 180 & 56 & 0.3 & $12 \pm 2$ & 120 \\
\hline MEP HyperCel $^{\mathrm{TM}}$ & $80-125$ & N/A & 20 & 6 & 5 & $\mathrm{~N} / \mathrm{A}$ \\
\hline Capto $^{\text {TM }}$ MMC & 80 & 70 & N/A & 2 & $\mathrm{~N} / \mathrm{A}$ & N/A \\
\hline $\begin{array}{l}\text { Capto }^{\mathrm{TM}} \mathrm{MMC} \\
\text { Impress }\end{array}$ & $25-39$ & 65 & $50-60$ & $4-5$ & N/A & $5-10$ \\
\hline
\end{tabular}

*The reported Dynamic Binding Capacity is measured at 10\% Breakthrough. 
Table 2. Fitted isotherm parameters for IgG adsorption on the MMM.

\begin{tabular}{|c|c|c|c|c|c|c|c|}
\hline Salt & $\mathrm{K}_{\mathrm{eq}}$ & $\mathrm{v}$ & $\mathrm{n}$ & $\begin{array}{c}\mathrm{Q}_{\max } \\
(\mathrm{mg} / \mathrm{mL})\end{array}$ & $\begin{array}{c}\mathrm{K}_{\mathrm{s}} \\
\left(\mathrm{M}^{-1}\right)\end{array}$ & $\begin{array}{c}\mathrm{K}_{\mathrm{p}} \\
(\mathrm{mL} / \mathrm{mg})\end{array}$ & $\begin{array}{c}\mathrm{C}_{\mathrm{s}, \min } \\
(\mathrm{M})\end{array}$ \\
\hline NaCitrate & 131 & 1.28 & 0.084 & 227 & 3.78 & -0.073 & 0.34 \\
\hline $\mathrm{NaCl}$ & 357 & 0.24 & 0.007 & 217 & -1.30 & -0.284 & - \\
\hline $\mathrm{NaSCN}$ & 301 & 1.12 & 0.068 & 221 & -1.79 & 0.042 & - \\
\hline
\end{tabular}


Table 3. Dynamic binding capacity at difference stages of breakthrough for MMM prepared using $21 \mathrm{~h}$ polymerization time.

\begin{tabular}{|c|c|}
\hline Breakthrough Percentage & DBC $(\mathrm{mg} / \mathrm{ml})$ \\
\hline $10 \%$ & 56 \\
\hline $50 \%$ & 80 \\
\hline $95 \%$ & 118 \\
\hline
\end{tabular}


Table 4. The effect of flow rate and sodium chloride concentration on MMM IgG dynamic binding capacity at $10 \%$ breakthrough and load productivity.

\begin{tabular}{|c|c|c|c|}
\hline $\begin{array}{c}\text { Flow rate } \\
(\mathrm{CV} / \mathrm{min})\end{array}$ & $\begin{array}{c}\mathrm{NaCl} \\
(\mathrm{mM})\end{array}$ & $\begin{array}{c}\mathrm{DBC}_{10 \%} \\
(\mathrm{mg} / \mathrm{mL})\end{array}$ & $\begin{array}{c}\text { Load Productivity } \\
(\mathrm{mg} / \mathrm{mL} / \mathrm{min})\end{array}$ \\
\hline 1 & 0 & 47 & 2.4 \\
\hline 1 & 150 & 38 & 3.0 \\
\hline 1 & 300 & 32 & 3.0 \\
\hline 3 & 0 & 45 & 7.2 \\
\hline 5 & 0 & 43 & 11.7 \\
\hline
\end{tabular}





. 